\title{
CORRESPONDENCE
}

\section{Autism-Current Status and Challenges in Pakistan}

Rida Fatima Saeed, Sara Mumtaz, Asma Saleem Qazi, Uzma Azeem Awan, Nosheen Akhtar

\section{ABSTRACT}

Autism is a group of neuro-developmental disabilities. It has an early-onset and can be diagnosed up to 3 years of age. It is characterized by disturbances in child's socialization, communication and cognitive abilities, and an unusual repetitive and restricted behavior. The majority of subjects have comorbid conditions. Males are more affected than females. ${ }^{1}$ The prevalence of autism is increasing in the world that could be due to improvement in diagnostic procedures and awareness in public and its worldwide prevalence is around $1 \% .{ }^{1}$

In Pakistan, there is a lack of widespread awareness and understanding about autism. We do not have exact prevalence data on this disease in Pakistan. However, according to the Autism Society of Pakistan, there are probably 350,000 children with this disease in the country. ${ }^{2}$ But the actual prevalence is believed to be much higher. Many cases remain undiagnosed because of unawareness, lack of medical facilities and stigma that is attached to mental conditions in Pakistan. ${ }^{3}$ In Pakistan, the distribution of disabilities includes mental retardation (MR), hearing impairment, visual impairment and physical disability. Autism is not considered as a disability in Pakistani society. Moreover, the term mental disability or cognition problem is considered as a social stigma or disgrace. Therefore, many people do not disclose the condition to avoid stigma. Another important reason of undiagnosed cases is lack of medical facilities and untrained doctors that categories autism under intellectual disability that is another condition. Many people especially from rural areas opt traditional therapies or go to preachers for healing.

Although there are individual efforts from public and private sectors in Pakistan to spread awareness about autism for proper management of subjects with this condition. But Pakistan has still a long way to go. Efforts are needed to change thinking and attitude of people about this disease and to provide medical facilities including specialist doctors for correct and early diagnosis of this disease. Early diagnosis can help in early management through proper medicines and psychological therapies. Government and private sector should work together to control and treat this disease. These steps are important to provide universal health coverage in Pakistan.

How to cite this: Saeed RF, Mumtaz S, Qazi AS, Awan US, Akhtar N. Autism-Current Status and Challenges in Pakistan. Life and Science. 2021;2(4): 202-202. doi: http://doi.org/10.37185/LnS.1.1.208

This is an Open Access article distributed under the terms of the Creative Commons Attribution License (http://creativecommons.org/licenses/by/4.0), which permits unrestricted use, distribution, and reproduction in any medium, provided the original work is properly cited

Department of Biological Sciences

National University of Medical Sciences, Rawalpindi

Correspondence:

Dr. Sara Mumtaz

Assistant Professor, Biological Science

National University of Medical Sciences, Rawalpindi

E-mail: sara.mumtaz@numspak.edu.pk

Funding Source: NIL; Conflict of Interest: NIL

Received: May 18, 2021; Revised: Jun 10, 2021

Accepted: Sep 02, 2021

\section{REFERENCES}

1. Lai MC, Lombardo MV, Baron-Cohen S: Autism. Lancet. 2014; 383: 896-910.

2. Shamsi DA: Autism: necessity of awareness and empathy. The Express Tribune. April 18, 2019; (accessed Feb 27, 2020). https://tribune.com.pk/story/1953109/6-autism-necessity-awareness-empathy/

3. Muqtadir A: Autism in Pakistan. The Express Tribune. November 30, 2019; (accessed Feb 27, 2020). https://tribune.com.pk/story/2108977/6-autism-in-pakistan/

4. Junaidi I: Autism not a recognised disability in Pakistan. Dawn. April 4, 2019; (accessed Feb 27, 2020). https://www.dawn.com/news/1473745 